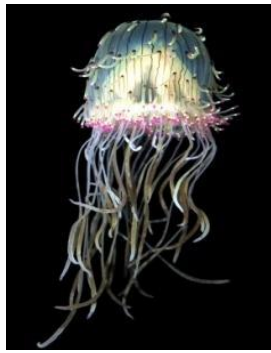

International Journal of Zoological Investigations

Contents available at Journals Home Page: www.ijzi.net

\title{
Emerging Issues and Sustainability of Booming Tilapia Production in India
}

Singh Atul K.

National Bureau of Fish Genetic Resources, Canal Ring Road, P.O. Dilkusha, Lucknow 226002, India

Received: $19^{\text {th }}$ September, 2019

Accepted: 24th October, 2019

https://doi.org/10.33745/ijzi.2019.v05i02.005

\begin{abstract}
Tilapia production in India is booming in recent years. Pond, tank and cage culture of the introduced improved strains of tilapia is being supported to compete the domestic as well as international market. The culture production is being intensified using modern tools such as cages and biofloc technology. At the same time several issues covering unregulated culture and breeding practices, unethical culture technology, and callous approach towards disease management are emerging now a days requiring immediate attention to make tialpia intensive production sustainable. Looking at the promises and prospects of intensive tilapia culture, proposals for future improvement in tilapia farming are suggested. There is need of responsible production and organised distribution of improved stocks, better formulated floating feeds, deployment of advanced aquaculture production systems, monosex culture and continued quarantine and tighter biosecurity standards.
\end{abstract}

Keywords: Tilapia; Culture; Monosex; Diseases; Management; Regulations

Citation: Singh Atul K.: Emerging Issues and Sustainability of Booming Tilapia Production in India. Intern. J. Zool. Invest. 5 (2): 43-51, 2019. https://doi.org/10.33745/ijzi.2019.v05i02.005

\section{Introduction}

Today world is teaming with aquaculture of most coveted introduced species the tilapia Oreochromis niloticus that is one of the early introductions in India (Singh and Lakra, 2011). Tilapia are second most farmed finfish after carp in the world. In Asia, it contributes about $72 \%$, Africa 19\% and America 9\% of the total world tilapia production (FAO, 2017). The Global production of tilapia has gone up to 6.5 million metric tons where China remains by far the major producer contributing 1.8 million metric tons; Bangladesh producing around 0.285 million metric tons while India still has a marginal share although the country is aspiring for a big targeted jump (Fig. 1). In India, there is an increased demand for low trophic-farmed tilapia species, in view of food security, foreign exchange earnings and employment. A demand-driven expansion of tilapia 
aquaculture production in India has been taken up to stimulate the local economy and thereby contributing to employment generation. Booming tilapia in India has been possible due to harmonizing with the world's

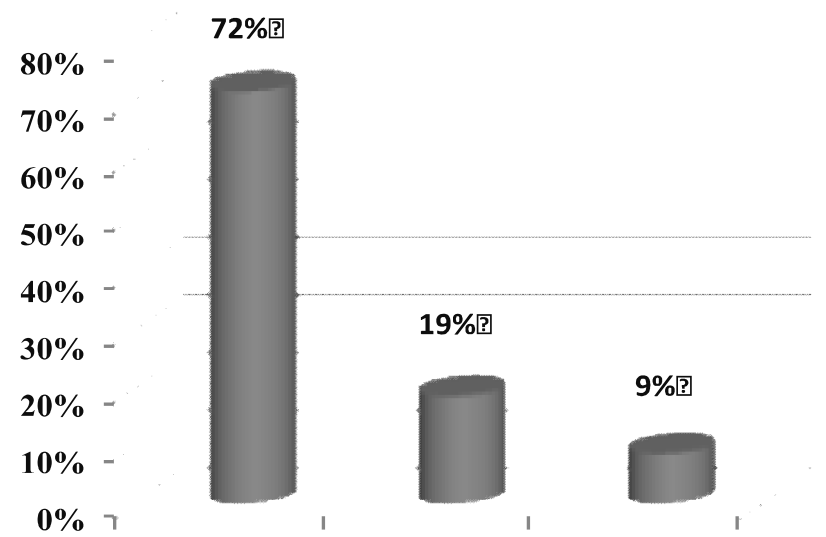

Asia Africa America

World Tilapia Production

Present Indian Production

Targeted Indian Production by 2030 cutting edge technology and trade. Present tilapia production in the country is although very limited, Marine Product Export Development Agency (MPEDA) is aiming at a very ambitious target to produce around 1.2

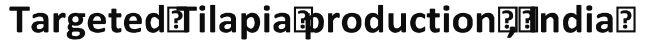

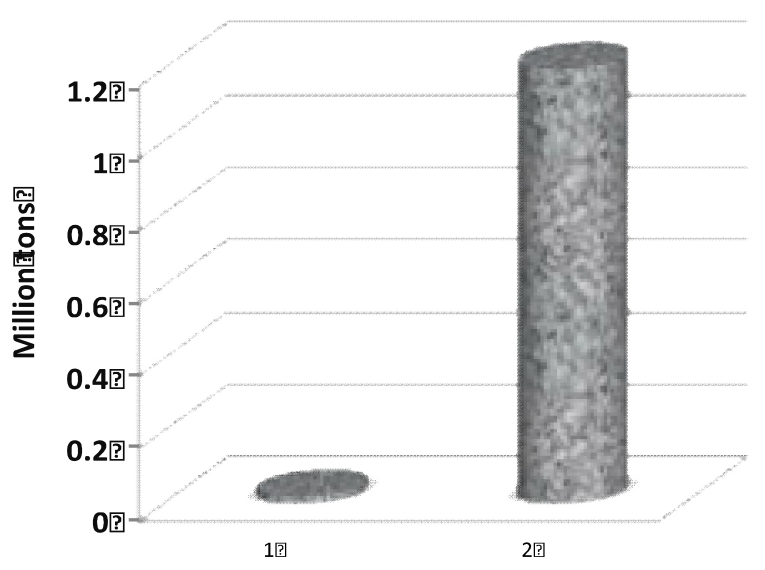

6.5 metric tons

20,000 tons 1200,000 tons?

Fig. 1: Tilapia production status and targeted production in India by 2030

million tons of tilapia in near future.

Early tilapia farming was based on extensive production technologies that involved primarily fertilization; low stocking densities, and some supplemental feeding (Sugunan, 1995). However, the initially introduced Mozambique tilapia (Oreochromis mossambicus) met with failure due to early maturation, lack of control over breeding and the ensuing slow growth rate gave unimpressive production. Larger-scale research and development attention began during late 1990s when the initial success of tilapia farming in its early phase of development was achieved primarily due to technological improvement that enabled aquaculturists to produce considerably high. Further, controlling unwanted reproduction was another issue although manual culling of females was initially the simplest way to ensure selection of faster-growing male tilapias. However, this method was labour intensive and prone to errors. Thereafter, hybrid production technologies provided an 
initial impetus for managing early sexual maturation and the prolific reproduction of tilapias. Introduction of the faster-growing and slowly maturing Nile tilapia (O. niloticus) in the late 1990s led to the development of several inter-specific hybrids such as golden tilapia (Singh and Lakra, 2011). Captive hybridization and rapid technology dissemination resulted in greater availability of tilapia hybrids later for aquaculture. This paper presents an assessment of over-all scenario of prospering tilapia culture into India and focuses on growing issues and concern to be addressed since aquaculturists are enthusiastically excited towards tilapia farming and large scale operations.

In India, there are five species of tilapia; the Oreochromis mossambicus was the first introduced tilapia species during 1952. Due to prolific breeding, it quickly gained the reputation of being a pest. The other species O. niloticus or Nile tilapia later became the choice of culture. The Government of India permitted its aquaculture in 2009, prescribing certain guidelines as a part of diversification of species for increasing overall fish production levels of the country. As the fish represents lower level in food chain, its culture has been considered economical and eco-friendly. As per existing guidelines, farming of only mono-sex male/sterile (through either hormonal manipulation or cross breeding) is permitted and species recommended is Nile tilapia and of late the genetically improved farmed tilapia (GIFT). The third species existing in India is $O$. urolepis honororum, which is available in Andaman and Nicobar and is cultivated there in ponds and tanks having production potential of over $1150 \mathrm{~kg} / \mathrm{ha} /$ culture cycle (Kiruba-Sankar et al., 2018). The fourth species reported from Chennai is O. aureus, which incidentally appeared and identified. The fifth one being Tilapia zilli that is available in large number in the Indira Gandhi canal in Rajasthan and the species is not under aquaculture (Singh and Lakra, 2011).

\section{Culture Production of Tilapia}

Aquaculture of tilapia is although an old endeavour (Sugunan, 1995) has taken a significant leap in the commercial fish farming in India looking forward to meeting the huge demand (Menaga and Fitzsimmons, 2017). Culture of $O$. niloticus has now been gearing up, particularly in Tamilnadu, Kerala, Andhra Pradesh, Orissa, Maharashtra, Rajasthan and West Bengal. Traditional extensive culture methods were replaced with semi-intensive and intensive production systems. Tilapia are also attractive as a co-cultured fish because of their potential to improve water quality, especially in penaeid shrimp ponds, by consuming plankton and detritus and by altering pathogenic bacterial populations while increasing marketable production (Menaga et al., 2019). Culture of GIFT has been successfully done in biofloc system as BFT helped improve optimum growth and better immune status of of the fish. The possibility of utilization of biofloc-based zero water exchange system to ensure bio-security and environmental sustainability in farming and inland saline water farming has been attempted and ensured (Menaga et al., 2019). GIFT strain of Tilapia at higher stocking densities 200-250 $\mathrm{m}^{-3}$ has been considered as optimum stocking density whereas higher stocking densities up to 350 nos $\mathrm{m}^{-3}$ may also be reared in the biofloc systems without compromising the growth and immunity (Menaga et al., 2019). 
Tilapia Culture in Ponds and Tanks

Culture of Nile tilapia Oreochromis niloticus (L.) is mostly practiced in tanks, ponds and of late in cages, which is clustered in Andhra Pradesh, Tamilnadu, Karnataka and Kerala states with an estimated production of around 20,000 metric tons while MPEDA has targeted its production close to 22,000 metric tons by the year 2020 (Menaga and Fitzsimmons, 2017). Although, tilapia is primarily produced as monoculture, however, tilapia aquaculture has also been adopted as polyculture with compatible local fish species for continuing increased production and improved sustainability (Wang and Lu, 2015). Tilapia has also been incorporated into polyculture with shrimp, providing an additional cash crop and reducing the incidence and severity of viral and bacterial diseases in shrimp. In pond culture, farmers have introduced tilapia as an additional polyculture species into traditional carp ponds. Polyculture of tilapia with carps is available in Andhra Pradesh, Gujarat and Tamil Nadu states. Shrimp and carp polyculture provides 3-5 per cent of national tilapia production.

Tilapia, Oreochromis mossambicus Peters, 1852, was the first species widely introduced for aquaculture while $O$. niloticus was introduced into India during late 1987 (Singh and Lakra, 2011). The aquaculture of $O$. niloticus expanded in the entire country, especially by private entrepreneurs. In 1995, Vorion Chemicals Ltd. Chennai claimed high production of hybrid red tilapia, popularly known as golden tilapia. The production of golden tilapia was claimed as 10 tons/culture cycle of six months. However, production collapsed for unknown reasons or due to unavailability of continuous seed supply. Later red tilapia production and sales increased due to a greater acceptance of red varieties, as well as the recognition of the value it adds to the final product (Lago et al., 2017). However, GIFT is still an accepted tilapia in the market (Bentsen et al., 2017). Genetically Improved Farmed Tilapia (GIFT) culture program developed by the World Fish Center, Penang, Malaysia has been now passed on to private industry for further enhancement of the fish in India. MPEDA has introduced GIFT to boost its exports and is planning to produce 12 lakh metric tons of GIFT worth 8000 crores INR in the next few years. Generally, tilapia fry $(1 \mathrm{~g})$ is reared in nursery ponds till $20-40 \mathrm{~g}$ for 5 to 8 weeks and then restocked into grow-out ponds. Male tilapia generally grows to $300-400 \mathrm{~g}$ in 5 to 6 months and reaches nearly 700-800 g in 9 months under mono-sex culture. To produce $400-500 \mathrm{~g}$ fish, common practice is to stock 6,000 to 8,000 males per acre in static water ponds with aeration or 20,000 to 28,000 males per acre where 20 per cent daily water exchange is exercised. After 6 months of feeding with good quality feeds, such ponds can produce 5 to $7 \mathrm{t} / \mathrm{ha}$.

\section{Tilapia Culture in Cages}

The development of cage and pen culture in India has substantially increased the reservoir fish production (Prabu et al., 2018; Sarkar et al., 2018). Floating cages have become the most popular system for rearing tilapia in India after Pangasianodon hypophthalmus in areas with suitable water quality, flushing rates and water depth (Sugunan, 1995; Sugunan and Katiha, 2004; Prabu et al., 2018; Sarka ret al., 2018). This practice has been growing in several countries, including China, Indonesia, Brazil, Bangladesh and India. MPEDA under central sector is endeavoring 
and pursuing hard to raise the tilapia production in cages, because Indian reservoirs and lakes have good potential for cultivating it. There is a plan of private fish exporters to invest over INR 100 crore in rearing tilapia in cages in lakes in Maharashtra and Rajasthan in the next four years with the technical support of MPEDA.

Culture of tilapia in cages installed in reservoirs or lakes although offer scope for increasing production, it is equally associated with environmental and social concern. The high nutrient inputs that water body receives in the form of unused feed and metabolic wastes may cause environmental problem due to eutrophication and inadvertent releases of the fish which are prone to damaging the ecosystem (Singh et al., 2013). It is important to conduct a scientific study to develop a safe methodology before such activities are spread, intensified and consolidated. At the same time, physical obstruction to the fishing activities of tradional fishers in these water bodies and resultant conflicts cropping-up owing to tilapia invasions should also be moderated through studies and way-outs. For cage culture, state fisheries departments have been exercising leasing and licensing procedures allowing cage culture in public waters without any scientific baseline and considering societal interests.

\section{Tilapia in Sewage Fed Fisheries}

Thousands of fish farmers had set up bheris or fishponds across 12,500 hectares sewage water on the eastern fringes of Kolkata city alone in West Bengal. The average yield of tilapia from wetlands/bheries is around 750 $\mathrm{kg} / \mathrm{ha} / \mathrm{yr}$ with the individual growth rate of 150-200 $\mathrm{g}$ in 3-4 months. Existing bheris or fishponds provide living support for some 50,000 cultivators and fish traders. Most of them are small-time private entrepreneurs who earn an income rearing 10,000 tons of wastewater-fed fish a year. The Kolkata model of rearing sewage-fed fish is used in a number of Indian cities, including Nagpur, Chennai and Bhopal.

\section{All Male Monosex Tilapia Production}

One of the key commercial technologies adopted in early 2000 was the production of monosex male tilapia. Tilapia fingerlings are fed with the androgen, 17- $\alpha$-methyl testosterone in diet, to produce all-male populations (Singh and Pandey, 1995). Dissemination of sex-reversal technology led to expansion of tilapia production around the world. However, unpredictable seed quality and concern over use of hormones for sex reversal led to genetics research leading into production of genetically male tilapia (GMT), where YY "super males" tilapia was produced. Super male tilapias have two Y-chromosomes instead of the usual $\mathrm{Y}$ and $\mathrm{X}$ chromosome thus producing only male progeny (Singh, 2013).

As the male tilapia is well adapted to supplementary feeding and due to its rapid growth, there is a huge profit in monosex tilapia farming (Omasaki et al., 2017). The currently operating hatcheries use $\alpha$-methyltestosterone to sex reverse fry for all-male production (Chakraborty et al., 2010; Singh, 2013). Most tilapia hatcheries are privately owned and stand-alone operations sell to a network of grow out farmers. Of late, a better simple and generic method of monosex production of tilapia was reported from India (Singh, 2013) as the farmers are relying on the 
monosex production technology from outside the country.

\section{Disease and Health Management}

Tilapia being hardy fish normally frequency of disease occurrence is low. Nevertheless, many bacterial diseases are ported in tilapia culture particularly in indoor systems (Chitmanat et al., 2016). There is a practice of using antibiotics, prebiotics and probiotics in tilapia culture which is a growing concern (Samwel et al., 2018). The effects of antibiotics, probiotics, prebiotics and alternative feed ingredients on the intestinal microbiota of tilapia in advanced tilapia culture techniques has been studied (Haygood, 2016) and it has been suggested that more research is needed into the microbial ecology, alternative feedstuff effects and economic impacts of modulating intestinal microbiota of tilapia so as to develop a sustainable tilapia production technology. Further, antibiotic resistance of isolated bacteria from tilapia farms may concern as zoonotic pathogens (Thongkao and Sudjaroen, 2017).

Beyond this, recently reported tilapia lake virus disease (TiLVD) has been found as a novel virus disease emerging as a potential threat to the global tilapia industry (Jansen et al., 2018). The disease was first reported from the freshwater lakes of Israel in 2014 which caused mass mortalities of tilapia (Jansen et al., 2018). Subsequently, the virus was reported in Fresh and brackish waters of Ecuador, Colombia, Egypt, Thailand, and India (Behra et al., 2018). The impact of tilapia lake virus disease on wild stocks may also be highly significant, both in economic terms and in relation to biodiversity and ecological effects (Reantaso, 2017; Jansen et al.,
2018). Recently, two tilapia cell lines have been developed for strategic control and prevention of TiLVD (Rajaswaminathan et al., 2018).

\section{Management Practices}

At present, aquaculturists prefer tilapia culture because culture techniques are simple and are available for them to adopt easily. Tilapia in Indian conditions has been observed to survive and grow well at $16-35^{\circ} \mathrm{C}$ temperature. Tilapia production from ponds and tanks is touching around 20000 tons annually. Its production from over a dozen of southern reservoirs ranges $30-70 \%$ of the reservoir productions (Sugunan and Katiha, 2004) while from the Ganga River System, its yield is in the range of 53.44 to 151.08 $\mathrm{kg} / \mathrm{km} /$ month. Tilapia is available even in some of the hill states where it is being produced twice a year. If modern farming methods and technology is used in tilapia farming, it would generate more income rendering a bright chance to contribute to our economy. Tilapia production has quadrupled over the past decade due to ease of aquaculture, marketability and stable market prices. Nevertheless, there is still a need for refinement of technologies being practiced and to ensure a strong genetic base of brood stock, seed production and its distributions, standard culture practice, effective farm management and health management so as to obtain desired final quality of the product. All these efforts must commensurate with developed government policies and regulations (Singh and Lakra, 2011; Singh et al., 2013; Roriz et al., 2017).

Following the existing regulatory framework available in the country, the 
introductions of improved strain the GIFT following quarantine and biosecurity, the tilapia production from pond, tank and cage may be safely promoted significantly elevating commercial productions and foreign exchange earnings. However, compliance with modern culture technologies, ethical standards, hygiene standards, and other relevant regulations in tilapia farming are yet a major concern for implementation. The excessive use of antibiotics and other chemical substances being indiscriminately used are a threat to tilapia aquaculture sustainability. This might negatively affect food safety and environmental conditions. There is need to draw sustainability standards and certification policy to increase value chain transparency and to enable producers to incorporate sustainability-related aspects in their farming practices. This will help Indian farmers to follow the Aquaculture Stewards Council (ASC) standards for tilapia farm-level standards and regulations for independent third-party audits and consumers' satisfaction. Such endeavor will support the environmental issues, conservation of biodiversity, natural habitats and water resources. The responsible use of resources is needed for aquaculture of tilapia. The protection of fish health as well as human health and socially responsible working conditions must be ensured.

Tilapia production in India has been now focusing on culture of red tilapia $O$. niloticus and farmers are trying to import them very often from different sources. The Ministry of Agriculture and Farmers Welfare has been facing the problem to clear the import as the surety of good strain and disease free tilapia mostly remains a question. It is suggested that improvement of tilapia production in India must include distribution of genetically proven improved stocks of the GIFT, better formulated floating feeds, deployment of advanced aquaculture production systems, continued quarantine and tighter biosecurity standards along with stringent monitoring at the state as well as central sector. For monosex production technology, farmers are mostly depending on the technology available abroad since the technology is not fully developed in the country for implementation. Therefore, application of tested monosex culture technique need be upscaled for commercial application which will boost up all male tilapia culture production. There is also an important need for refinement of technologies to ensure broodstock enhancement and sufficient seed production, safe and improved culture practice, effective management of diseases and to ensure consumers' acceptable quality of the product. Advances in information and communication technology will help fish farmers and other aquaculture stakeholders to adopt better management practices. These advances should range from high-tech modeling and monitoring systems used to improve the environmental and economic performance of tilapia farming. The available regulatory mechanisms in the country for responsible culture must strictly be followed to ensure sustainable growth of the sector. If needed the existing guideline on tilapia culture and breeding should be revisited for modifications and amendments with stricter enforcements.

\section{References}

Behra BK, Pradhan PK, Swaminathan R, Sood N, Prasenjit P, Das A, Kumar R,Yadav MK, Dev AK, Parida PK, Das BK, Lal KK and Jena JK. (2018) Emergence of tilapia lake virus associated with 
mortalities of farmed Nile tilapia Oreochromis niloticus (Linnaeus 1758) in India. Aquaculture 484:168-174.

Bentsen Hans B, Bjarne G,Ambekar E Eknath, Marietta S Palada de Vera, Ravelina R. Velasco, Jocedel C Danting, Edna ED, Felicisima ML, Ruben AR, Tereso AA, Melchor MT and Raul WP (2017) Genetic improvement of farmed tilapias: response to five generations of selection for increased body weight at harvest in Oreochromis niloticus and the further impact of the project. Aquaculture 468:206-217.

Chakraborty SB,Mazumdar D and Banerjee S (2010) Determination of ideal stocking density for cage culture of monosex Nile tilapia (Oreochromis niloticus) in India. Proc. Zool. Soc. 63:5357.https://doi.org/10.1007/s12595-010-0007-3.

Chitmanat C, Phimphakan L, Niwooti W, Jongkon P and Louis L (2016) Tilapia diseases and management in river-based cage aquaculture in northern Thailand. Journal of Applied Aquaculture 28: 9-16.

FAO (2017) Global Aquaculture Production. http://www.fao.org/fishery/statistics/globalproduction/en (Accessed 20 March, 2019).

Georgia DR, Marina Karina de VCD, Ian A, Garner VS, Picao GA (2017) Characterization of tilapia farming in net cages at a tropical reservoir in Brazil. Aquaculture Reports 6:43-48.

Haygood Alyssa M (2016) Strategies to modulate the intestinal microbiota of Tilapia (Oreochromis sp.) in aquaculture: a review. Reviews in Aquaculture. First published: 20

June 2016https://doi.org/10.1111/raq.12162.

Jansen MD, Ha TD, Chadag VM (2018) Tilapia lake virus: a threat to the global tilapia industry? Reviews in Aquaculture. First published:04 May 2018https://doi.org/10.1111/raq.12254.

Kiruba-Sankar R, Praveen Raj J, Saravanan K, Lohith KK, Raymond J AJ, AyyamV and Dam Roy S (2018) Invasive species in freshwater ecosystems - threats to ecosystem services In: Biodiversity and Climate Change Adaptation in Tropical Islands. http://dx.doi.org/10.1016/B978-0-12-813064-3. 00009-0 Copyright (c) 2018 Elsevier Inc.

Lago Aline de A, Tiago TR, Marco ADD, Rilke Tadeu Fde F and Alexandre WSH (2017) The development of genetically improved red tilapia lines through the backcross breeding of two Oreochromis niloticus strains. Aquaculture 472:17-22.

Menaga M and Fitzsimmons K. (2017) Growth of tilapia industry in India. World Aquaculture 48: 49-52.
Menaga M, Felix S, Charulatha M, Gopalakannan A and Panigrahi A (2019) Effect of in-situ and ex-situ biofloc on immune response of genetically improved farmed tilapia. Fish Shellfish Immunol.92:698-705.

Omasaki SK, Janssen K, Besson M and Komen H (2017) Optimization of Nile tilapia breeding schemes for monosex culture conditions in smallholder production systems. Aquaculture 481: 124-132.

Prabu E, Felix, N, Ahilan B, Antony Cheryl, Uma A and Ruby P(2018) Cage culture of tilapia with respect to nutrition and feeding. J. Aquaculture Tropics33: 1933.

Rajaswaminathan T, Charan R, Raj Kumar, Arathi D, Basheer VS, Pravata KP and Sood N (2018) Derivation of two tilapia (Oreochromis niloticus) cell lines for efficient propagation of Tilapia Lake Virus (TiLV). Aquaculture 492: 206-214.

Reantaso MB(2017) Tilapia lake virus (TiLV) caused by an orthomyxo-like virus (Family Orthomyxoviridae) threatening cultured and wild stocks of tilapia. FAO Aquaculture News 1. 57: 9-11.

Roriz GD, Marina Kde, Veiga CD, Ian AG, Vitor S and Picao G. (2017) Characterization of tilapia farming in net cages at a tropical reservoir in Brazil. Aquaculture Reports 6:43-49.

Samwel M, Limbu Li Z, Sheng-Xiang S, Mei-Ling Zhang and Zhen-Yu D. (2018) Chronic exposure to low environmental concentrations and legal aquaculture doses of antibiotics cause systemic adverse effects in Nile tilapia and provoke differential human health risk. Environment International 115: 205-219.

Sarkar UK, Sandhya KM, Mishal P, Karnatak G, Lianthuamluaia, Kumari S, Panikkar P, Palaniswamy R, Karthikeyan M, Sibina SM, Paul TT, Ramya VL, Rao DSK, Feroz Khan M, Panda D and Das BK (2018) Status, Prospects, Threats, and the Way Forward for Sustainable Management and Enhancement of the Tropical Indian Reservoir Fisheries: An Overview. Reviews in Fisheries Science and Aquaculture 26:155-175.

Singh AK, Kumar D, Srivastava SC, Abubakar A, Jena JK and Sarkar UK (2013) Invasion and impacts of alien fish species in the Ganga river, India. Aquatic Ecosystem Health Management 16:408-414.

Singh AK and Lakra WS (2011) Risk and benefit assessment of alien fish species of the aquaculture and aquarium trade into India. Reviews in Aquaculture 3: 3-18.

Singh AK and Pandey AK (1995) Effect of long photoperiod on growth survival and sex reversal of 
androgenizing tilapia, Oreochromis mossambicus. Nat. Acad. Sci. Letter India 18:227- 231.

Singh AK(2013) Introduction of modern endocrine techniques for the production of monosex population of fishes. Gen. Comp. Endocrinol. 181: 146-155.

Sugunan VV (1995) Reservoir Fisheries of India, Rome: Food and Agriculture Organization of the United Nations pp 243.

Sugunan VV (2000) Ecology and fishery management of reservoirs in India. Hydrobiologia 430:121-147.

Sugunan VV and Katiha PK (2004) Impact of stocking on yield of small reservoirs in Andhra Pradesh, India. Fish Manage. Ecol. 11:65-69.
Thongkao K and Sudbjaroen Y (2017) Human pathogenic bacteria isolation from tilapia fishes (Oreochromis niloticus), a possible reservoir of zoonotic transmission. Annals Tropical Medicine Public Health 10: 1563-1568.

Wang M and Maixin Lu (2015) Tilapia polyculture: a global review. Aquaculture Research First published: $30 \quad$ January 2015. https://doi.org/10.1111/are.12708. 